\title{
BMJ Open Variation in coded frailty syndromes in secondary care administrative data: an international retrospective exploratory study
}

\author{
John T Y Soong (D) , ${ }^{1,2}$ Sheryl Hui-Xian Ng, ${ }^{3}$ Kyle Xin Quan Tan, ${ }^{3}$ Jurgita Kaubryte, ${ }^{4}$ \\ Adrian Hopper ${ }^{5}$
}

To cite: Soong JTY,

$\mathrm{Ng} \mathrm{SH}-\mathrm{X}$, Tan KXQ, et al. Variation in coded frailty syndromes in secondary care administrative data: an international retrospective exploratory study. BMJ Open 2022;12:e052735. doi:10.1136/ bmjopen-2021-052735

- Prepublication history and additional supplemental material for this paper are available online. To view these files, please visit the journal online (http://dx.doi.org/10.1136/ bmjopen-2021-052735).

Received 26 April 2021 Accepted 07 January 2022

Check for updates

(C) Author(s) (or their employer(s)) 2022. Re-use permitted under CC BY-NC. No commercial re-use. See rights and permissions. Published by BMJ.

${ }^{1}$ Department of Medicine, National University Hospital, Singapore

${ }^{2}$ Yong Loo Lin Medical School, National University of Singapore, Singapore

${ }^{3}$ Saw Swee Hock School of Public Health, National University of Singapore and National University Health

System, Singapore

${ }^{4}$ Dr Foster Telstra Health Ltd,

London, UK

${ }^{5}$ Guy's and Saint Thomas' NHS Foundation Trust, London, UK

Correspondence to

Dr John T Y Soong;

John_Soong@nuhs.edu.sg

\section{ABSTRACT}

Objectives Challenges with manual methodologies to identify frailty, have led to enthusiasm for utilising large-scale administrative data, particularly standardised diagnostic codes. However, concerns have been raised regarding coding reliability and variability. We aimed to quantify variation in coding frailty syndromes within standardised diagnostic code fields of an international dataset.

Setting Pooled data from 37 hospitals in 10 countries from 2010 to 2014.

Participants Patients $\geq 75$ years with admission of $>24$ hours ( $N=1404671$ patient episodes).

Primary and secondary outcome measures Frailty syndrome groups were coded in all standardised diagnostic fields by creation of a binary flag if the relevant diagnosis was present in the 12 months leading to index admission. Volume and percentages of coded frailty syndrome groups by age, gender, year and country were tabulated, and trend analysis provided in line charts. Descriptive statistics including mean, range, and coefficient of variation (CV) were calculated. Relationship to in-hospital mortality, hospital readmission and length of stay were visualised as bar charts.

Results The top four contributors were UK, US, Norway and Australia, which accounted for $75.4 \%$ of the volume of admissions. There were 553595 (39.4\%) patient episodes with at least one frailty syndrome group coded. The two most frequently coded frailty syndrome groups were 'Falls and Fractures' ( $\mathrm{N}=336$ 087; 23.9\%) and 'Delirium and Dementia' ( $N=221$ 072; 15.7\%), with the lowest CV. Trend analysis revealed some coding instability over the frailty syndrome groups from 2010 to 2014. The four countries with the lowest CV for coded frailty syndrome groups were Belgium, Australia, USA and UK. There was up to twofold, fourfold and twofold variation difference for outcomes of length of stay, 30-day readmission and inpatient mortality, respectively, across the countries.

Conclusions Variation in coding frequency for frailty syndromes in standardised diagnostic fields are quantified and described. Recommendations are made to account for this variation when producing risk prediction models.
Strengths and limitations of this study

- A large cohort of $>1.4 \mathrm{~m}$ patient episodes from 37 hospitals across 10 countries are included.

- Variation in frequency of coding for frailty syndromes are quantified in multiple ways, namely between countries, over time and between frailty syndromes.

- The dataset was frailty complete with only $0.17 \%$ missing data.

- The frailty measurement model used has had validation in multiple settings.

- Institutions contributing to the dataset are selfselected academic tertiary centres and the findings may not be generalisable to other secondary care institutions.

\section{INTRODUCTION}

Population ageing is often associated with increased chronic illness and functional dependence, leading to a state of poor resilience and heightened vulnerability, namely frailty. ${ }^{1}$ Frailty is a multidimensional syndrome characterised by loss of physiological reserve and the accumulation of deficits, resulting in heightened vulnerability to external stressors. ${ }^{2}$ Frailty is associated with excess mortality, morbidity, disability, emergency hospital admission and resource utilisation. ${ }^{34}$

There is mounting evidence that frailty (or at least it's complications) can be prevented or delayed..$^{5}$ Robust, reliable and widespread identification of frailty remains problematic. Existing instruments to measure frailty are manually intensive, require specialised apparatus, are often clinically unfeasible, susceptible to operator error or have yet to demonstrate clinical utility for improving quality of patient care or clinical outcomes. ${ }^{6}$

What characteristics would make an ideal dataset to measure frailty? It would have complete capture of the target population 
and be linked at patient level to provide the ability for observation across different settings (eg, community to hospital). It would collect longitudinal data, allowing for tracking of information over time. It would be continuously collected, direct from contemporaneous records to reduce sampling error or duplication. There would be embedded data validation processes to ensure reliability and accuracy. Financial and human resource costs to maintain and curate this database would be low and affordable. It would contain variables suitable for measuring performance of healthcare organisations, are standardised and conform to high health informatics standards. ${ }^{8-10}$ It would allow for rapid feedback to participating organisations.

While there are currently no datasets that fulfil all these criteria completely, routinely collected administrative data do fulfil many of these criteria, making an attractive case for secondary uses in identifying frailty such as population segmentation, case-mix adjustment or clinical registries. Consequently, there is increasing interest in using these data for the purposes of widespread frailty identification, ${ }^{11-14}$ often using standardised diagnostic codes. There have been some limitations noted with this methodology. The accuracy of diagnostic coding has been challenged, with potential under capture, for example, functional dependence codes. Though rich, many administrative datasets do not contain variables previously identified to be associated with frailty. Administrative data have rigorous processes for cleaning and validation, which occur after the acute hospitalisation episode. While this ensures high data informatics standards, these processes are time-consuming, limiting contemporaneousness of the information. There are diverse methods for standardising diagnostic codes which limit generalisability between populations and settings. Frequency of diagnostic coding has been known to shift overtime. ${ }^{15}$ Understanding data heterogeneity and variation in frequency of coding for frailty using standardised diagnostic codes is therefore a research priority.

This study aims to quantify potential variation in frequency of coding for frailty in standardised diagnostic codes. We use a previously published methodology of grouping standardised diagnostic codes into frailty syndromes. ${ }^{12}$ It will compare and contrast diagnostic coding frequency and variation of coding between countries, over time and between frailty diagnostic archetypes within a pooled international secondary care dataset spanning 10 countries over 5 years. Additionally, it will explore the relationship of coded frailty to important clinical outcomes, namely in-hospital mortality, non-elective hospital admission and long length of hospital stay.

\section{METHODS}

\section{Data sources}

The Global Comparators programme was an international hospital collaborative which ran from 2011 to 2017. Participating secondary care institutions contributed and pooled administrative data for the purposes of benchmarking performance in order to better understand variations in clinical practice and outcomes, with the aim of disseminating international best practice. This dataset was then enriched with administrative data from National University Hospital (NUH) in Singapore for completion. This final dataset pooled secondary care data from 37 hospitals in 10 countries from 2010 to 2014. Data were extracted from the Dr Foster Global Comparators dataset and NUH data systems using established methods for data cleaning and anonymisation. ${ }^{16}$

\section{Study population}

All patients $\geq 75$ years old with admissions of $>24$ hours who had both elective or non-elective hospital admission were included in the analysis. Patient spells were excluded if the age, sex or length of stay was recorded as missing or invalid, or the admission was planned and the patient discharged home on the same day, or the admission was unplanned but no procedure was undertaken and the patient went home after a recorded length of stay less than 2 days. This was to exclude records with inadequate quality data, and patients admitted into observations units or day-case attendances, which are outpatient based. Overall, only $0.17 \%$ of data were missing.

\section{Variable definitions}

Frailty syndromes are clinically recognised states which occur disproportionately more frequently in vulnerable older persons. They are high-order phenomena, resulting from the interaction of accumulating deficits and environmental factors. They confer a higher risk of death, institutionalisation, disability and poor quality of life. National expert consensus and guidelines recommend the use of frailty syndromes as a possible methodology for frailty identification, particularly in the acute hospitalisation setting. ${ }^{17-20}$

Individual patient cases correspond to a spell covering a patient's total length of stay at a hospital. At this data level, seven groups of frailty syndromes were coded within International Statistical Classification of Diseases, Injuries and Causes of Death (ICD) diagnostic coding groups, and within all available diagnostic fields, namely Dementia and Delirium, Mobility Problems, Falls and Fractures, Pressure Ulcers and Weight Loss, Incontinence, Dependence and Care, as well as Anxiety and Depression. ${ }^{12}$ These diagnostic codes are collated by clinical coders for administrative purposes after completion of the acute hospitalisation episode. As the Global Comparators data set comprised hospitals which used different revisions of ICD (revision 9 and 10). ICD-10 is the more recent iteration of the coding framework, and has character length, allows alphabets (while ICD-9 is purely numeric) and has added emphasis on modern technology to allow better coding for procedures. The equivalent diagnostic codes for both versions were compiled (online supplemental appendix 1). 
The dataset contained flags for all-cause in-hospital mortality and 30-day non-elective readmission. Length of hospital stay was calculated as the difference date of discharge from date of admission and calculated in days. Previous risk prediction models using this methodology for coding frailty syndromes have demonstrated significant predictive capacity for the outcomes above, after adjustment for age, gender, country and comorbidity. ${ }^{12}$

\section{Statistical analysis}

For descriptive statistics, the volume and percentages of coded frailty syndrome groups by age, gender, year and country are tabulated. For temporal analysis, percentages of coded frailty syndrome by country by monthly aggregate are plotted as line charts. ${ }^{21}$ To explore variation, the range and mean between countries for coding of frailty syndromes by yearly aggregate are plotted as line charts. Coefficient of variation (CV) is a standardised measure of data dispersion around the mean. This was calculated by country and frailty syndrome group. Unadjusted In-hospital mortality and median length of hospital stay by country and frailty syndrome are plotted on bar charts for comparison of outcomes. The readmission rate presented in this study represents any non-elective readmission to the respective hospital within 30 days, with index admission episodes that ended with in-patient mortality excluded. Comparison of categorical variables for significance are calculated by $\chi^{2}$ test. All analyses were done on Microsoft SQL Server and Microsoft Excel.

\section{RESULTS}

\section{General descriptive statistics}

A total of 1404671 patient spells were included in the analysis, from 37 hospitals across 10 countries. The top four contributors were UK, USA, Norway and Australia, accounting for $75.4 \%$ of the volume of admissions. The two most frequently coded frailty syndrome groups were group 3 Falls and Fractures, and group 1 Delirium and Dementia. There were 553595 (39.4\%) patient episodes with at least one frailty syndrome group coded. There was variation between countries in the frequency of coding for having at least one frailty syndrome, from 2871 (11.9\%) to 108491 (56.5\%). Table 1 displays the total volume and percentage of coded frailty syndromes by country and frailty syndrome group. The top five countries with highest frequency for frailty syndrome coding (at least one frailty syndrome coded) in descending order were Australia, USA, UK, Belgium and Singapore.

For the year 2013, the percentage of patients with at least one frailty syndrome coded increased with age, with $31 \%$ of patients between the age of 75-79 being coded with at least one frailty syndrome group compared with $59 \%$ over the age of 90. There were 164508 (54\%) females included in the analysis, and there were $76712(47 \%)$ females with at least one frailty syndrome group coded compared with $50284(22 \%)$ males $(\mathrm{p}<0.001)$. Non-elective admissions comprised of $231054(76 \%)$ patient episodes, and 110

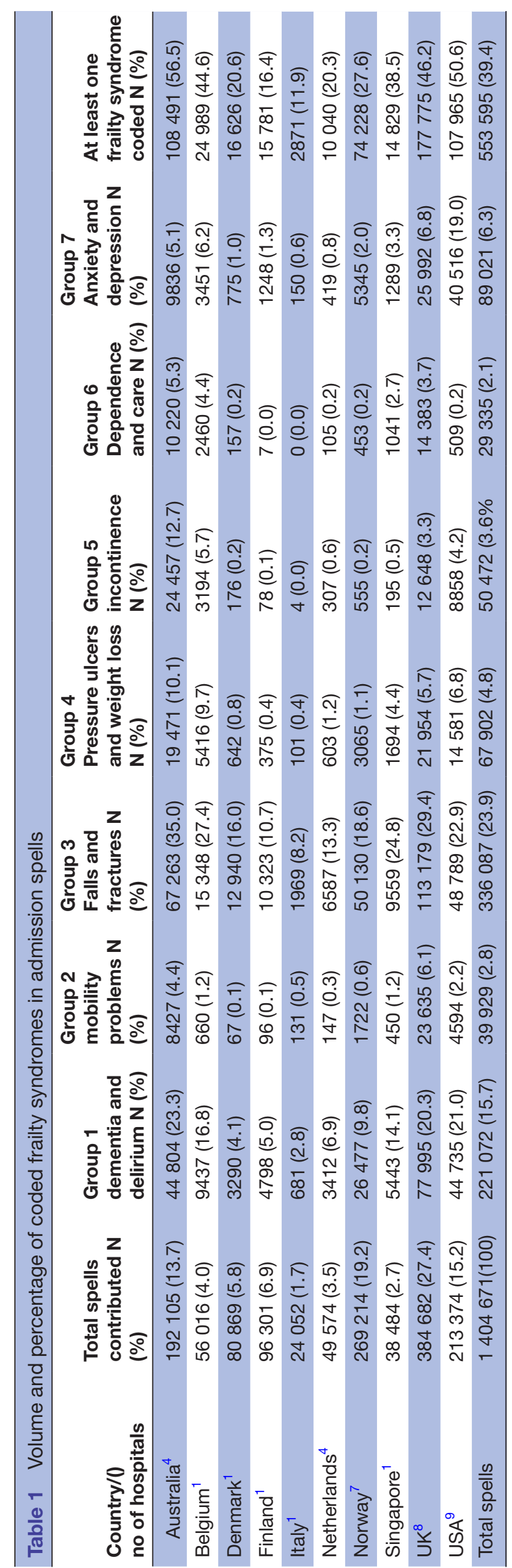


$395(48 \%)$ of the non-elective admissions had at least one frailty syndrome group coded, compared with 16601 $(22 \%)$ elective patient episodes $(\mathrm{p}<0.001)$.

\section{Trend analysis of coded frailty syndromes by country}

Online supplemental appendix 2 displays the percentage frequency of each frailty syndrome group by country aggregated at monthly units from 2010 to 2014. This was calculated as volume of admission for month coded with frailty syndrome divided by the total volume of admission for the month. Frequency of coding for at least one frailty syndrome was fairly stable for this time period except for the Netherlands, which showed a decreasing trend from 2010 to 2011, sharp rises at the beginning and end of 2012, which was not sustained in 2013 to 2014.

There was some coding instability over time noted for each of the frailty syndrome groups. The top five countries for frequency of coding of 'Delirium and Dementia' were Australia, UK, USA, Belgium and Singapore in descending order, accounting for $83 \%$ of coding volume for the group. There was a gradual increase in frequency of coding in UK (17.5\% to $25.1 \%$ ) and Norway (5.2\% to $11.9 \%$ ) from 2011 to 2014.

The top two countries for frequency of coding of 'Mobility Problems' were UK and Australia, accounting for $80 \%$ of coding volume for the group. Sharp increases in coding frequency were noted in UK (4.2\% to $9.9 \%)$ from 2011 to 2013, but this was not sustained in 2014. There was a gradual decline in coding frequency in Australia occurred from 5.3\% to 3.6\% from 2010 to 2014, while a gradual and sustained increase in coding frequency in USA (1.2\% to $3.4 \%$ ) was noted for the same time period.

The top five countries for frequency of coding of 'Falls and Fractures' in descending order were Australia, UK, Belgium, Singapore and USA, accounting for $76 \%$ of the volume of coding for the group. There was a gradual increase in coding in UK (26\% to $33.4 \%$ ) from 2010 to 2013 but unsustained in 2014. There were fluctuating levels of coding in the Netherlands, with a decrease from $11.7 \%$ to $8.4 \%$ from 2010 to 2011, followed by a sharp increase to $19.3 \%$ from the end of 2011 to 2013, which was unsustained.

The top five countries for frequency of coding for 'Pressure Ulcers and Weight Loss' in descending order were Belgium, Australia, USA, UK and Singapore, accounting for $93 \%$ of the coding volume for the group, where there was a clear demarcation of coding frequencies from the rest of the countries. There was a sharp increase in frequency of coding in Belgium (7.9\% to $14.1 \%$ ) and UK $(4.2 \%$ to $8.1 \%)$ from 2011 to 2013 , but unsustained subsequently.

Australia had the most frequent coding for 'Incontinence' by a large margin, accounting for $48 \%$ of the volume of coding for the group, followed by Belgium, USA and UK in descending order. These top four countries accounted for $97 \%$ of the volume of coding for the group, with a clear demarcation of coding frequencies from the rest of the countries.

The top four countries for frequency of coding of 'Dependence and Care' in descending order were Australia, Belgium, UK and Singapore, accounting for $96 \%$ of volume of coding for the group, with a clear demarcation of coding frequency for the rest of the countries. Australia $(6.1 \%$ to $4.9 \%)$ and UK $(4.4 \%$ to $2.5 \%)$ demonstrated a slow decline in frequency of coding from 2010 to 2014. There was an increase in frequency of coding in Belgium 4.9\% to 6.9\% from 2010 to 2013 that was unsustained.

USA had the most frequent coding for 'Anxiety and Depression' by a large margin, accounting for $46 \%$ of the volume of coding for the group, followed by UK, Belgium, Australia and Singapore in descending order. These top five countries accounted for $91 \%$ of volume of coding for the group. The frequency of coding gradually increased in USA (17.9\% to $21.4 \%)$ and UK (4.6\% to $8.8 \%)$ from 2010 to 2014.

\section{Trend analysis of coded frailty syndromes within country}

Online supplemental appendix 3 displays the percentage frequency of coded frailty syndrome groups aggregated monthly for each country. Generally, 'Falls and Fractures' and 'Dementia and Delirium' were the most frequently coded frailty syndrome groups across all the countries, accounting for $39.7 \%$ of all coded frailty syndrome groups overall, with $23.9 \%$ and $15.7 \%$ of overall volume, respectively. There was also a sustained gradual increase in coding for 'Anxiety and Depression' (4\% to $8 \%$ ) in all countries.

There was a sustained increase in coding for 'Pressure Ulcers and Weight Loss' from 7\% to 13\% from mid-2012 to 2014 in Belgium. Between 2011 to early 2013, there was large baseline variation of coding frequency in Italy, mainly due to fluctuations in coding for 'Falls and Fractures' and 'Dementia and Delirium'. In the Netherlands, there were sharp increases in coding for 'Falls and Fractures' and 'Dementia and Delirium' from the end 2011 to 2014. In the USA, the top three coded groups were 'Falls and Fractures', 'Dementia and Delirium' and for 'Anxiety and Depression' with 21\%, 22.9\% and 19\% of overall volume of coding, respectively.

\section{Variation of coding for frailty syndromes between countries} Figure 1 displays the range and of percentage coded frailty syndrome groups across the countries aggregated yearly, and SD and CV for 2013. The largest overall range was from 'Dementia and Delirium, 'Falls and Fractures' and 'Anxiety and Depression' with average range of $20.6 \%$, $26.1 \%$ and $18.2 \%$, respectively. The smallest overall range was from 'Mobility Problems' and 'Dependence and Care' with average range of $6.6 \%$ and $5.4 \%$, respectively. However, 'Dementia and Delirium' and 'Falls and Fractures' had the highest frequency of coding compared overall (mean of $12.8 \%$ and $21.1 \%$, respectively), while 'Mobility Problems' and 'Dependence and Care' were 


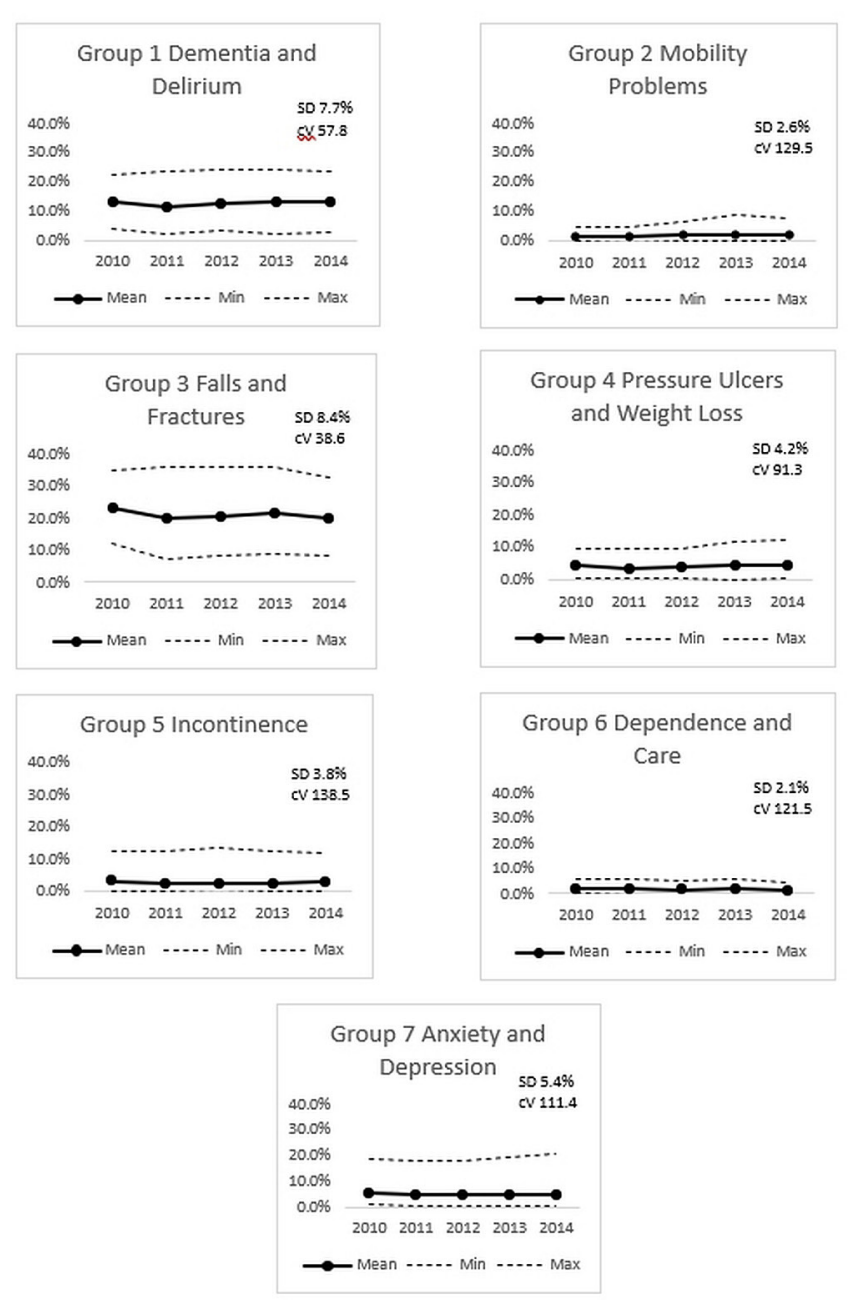

Figure 1 Range and mean of percentage coded frailty syndrome groups across the countries from 2010 to 2014, with SD and coefficient of variation (CV) for 2013.

the least frequently coded groups (mean $1.7 \%$ and $1.8 \%$, respectively). The range increased for 'Mobility Problems from 2011 to 2013 and 'Pressure Ulcers and Weight Loss' from 2012 to 2014, with little effect on mean, and mainly due to increases in maximum range. 'Dementia and Delirium' and 'Falls and Fractures' had the least variation across the countries with CV (SD divided by mean) of 57.8 and 38.6, respectively. Group 5 Incontinence, group 2 Mobility Problems and group 6 Dependence and Care had the highest variation with CV of 138.5, 129.5 and 121.5 , respectively.

\section{Variation of coding for frailty syndromes within countries}

Figure 2 displays the mean and range of coded frailty syndromes for each country aggregated yearly from 2010 to 2014, and SD and CV for 2013. The four countries with overall highest mean across frailty syndrome groups coded were Australia, UK, USA and Belgium with mean of $13.7 \%, 10.9 \%, 10.8 \%$ and $10.2 \%$, respectively. The countries with the largest overall range across the frailty syndrome groups were Australia, UK, Belgium, Singapore and USA with range of $30.6 \%, 26.3 \%, 26.2 \%, 24.6 \%$ and
22.7\%, respectively. The Netherlands showed a sharp rise in range across frailty syndrome groups between 2011 and 2013 with an associated gradual increase in mean as frequency of coding increased. There was a gradual increase in maximum range ( $26.9 \%$ to $32.9 \%$ ) with associated increase in mean (9.1\%-12.7\%) from 2010 to 2013.

The four countries with the lowest variation of coding for frailty syndrome groups were Belgium, Australia, USA and UK with CV of 77.6, 80.5, 82.3 and 82.6, respectively. These countries also had the highest overall mean level of coding for frailty syndrome groups. The countries with the highest variation of coding for frailty syndrome groups were Denmark, Italy and Finland with CV of 166.1, 164.4, 147.5, respectively, and lowest overall mean level of coding for frailty syndrome groups.

\section{Outcomes}

Online supplemental appendix 4 displays the outcomes by country and frailty syndrome group, namely length of hospital stay, 30-day non-elective readmission and in-hospital mortality. The distribution of length of stay for all countries was very positively skewed. A twofold difference between countries for overall mean (5.6-11.5 days) and median (4-7 days) length of hospital stay was noted. Generally, a longer median length of hospital stay was observed across all frailty syndrome groups compared with all $\geq 75$ years old across the countries.

A fourfold difference in 30-day non-elective hospital readmission rate $(4.7 \%-18 \%)$ was noted between the countries. Generally, 30-day non-elective readmission rate was not visibly higher in frailty syndrome groups compared with all $\geq 75$ years old across the countries, with some exceptions. For example, in Italy and Belgium, $22.2 \%$ and $8 \%$ of patient episodes coded with 'Pressure Ulcers and Weight Loss' were associated with hospital readmission compared with $4.7 \%$ and $6.8 \%$ of all $\geq 75$ years old, respectively. In Finland, $18.8 \%$ of patients coded with 'Mobility Problems' compared with $9.4 \%$ of all $\geq 75$ years old and $20 \%$ of patients coded with 'Incontinence' compared with $9.4 \%$ ' of all $\geq 75$ years old was associated with hospital readmission.

A twofold difference of in-hospital mortality was noted between the countries $(8.5 \%-3.8 \%)$. Higher mortality rates were seen in those coded with 'Dementia and Delirium' and 'Pressure Ulcers and Weight loss' compared with all $\geq 75$ years old, but not the other frailty syndrome groups. This effect was seemingly greater for those coded with 'Pressure Ulcers and Weight Loss'.

Table 2 describes the CV across all frailty syndrome groups within country for each outcome for the year 2013. There was no correlation or association between variation across all frailty syndrome groups within country to outcomes (online supplemental appendix 5).

\section{DISCUSSION}

This study finds that coded frailty syndromes within the standardised diagnostic fields of an international 

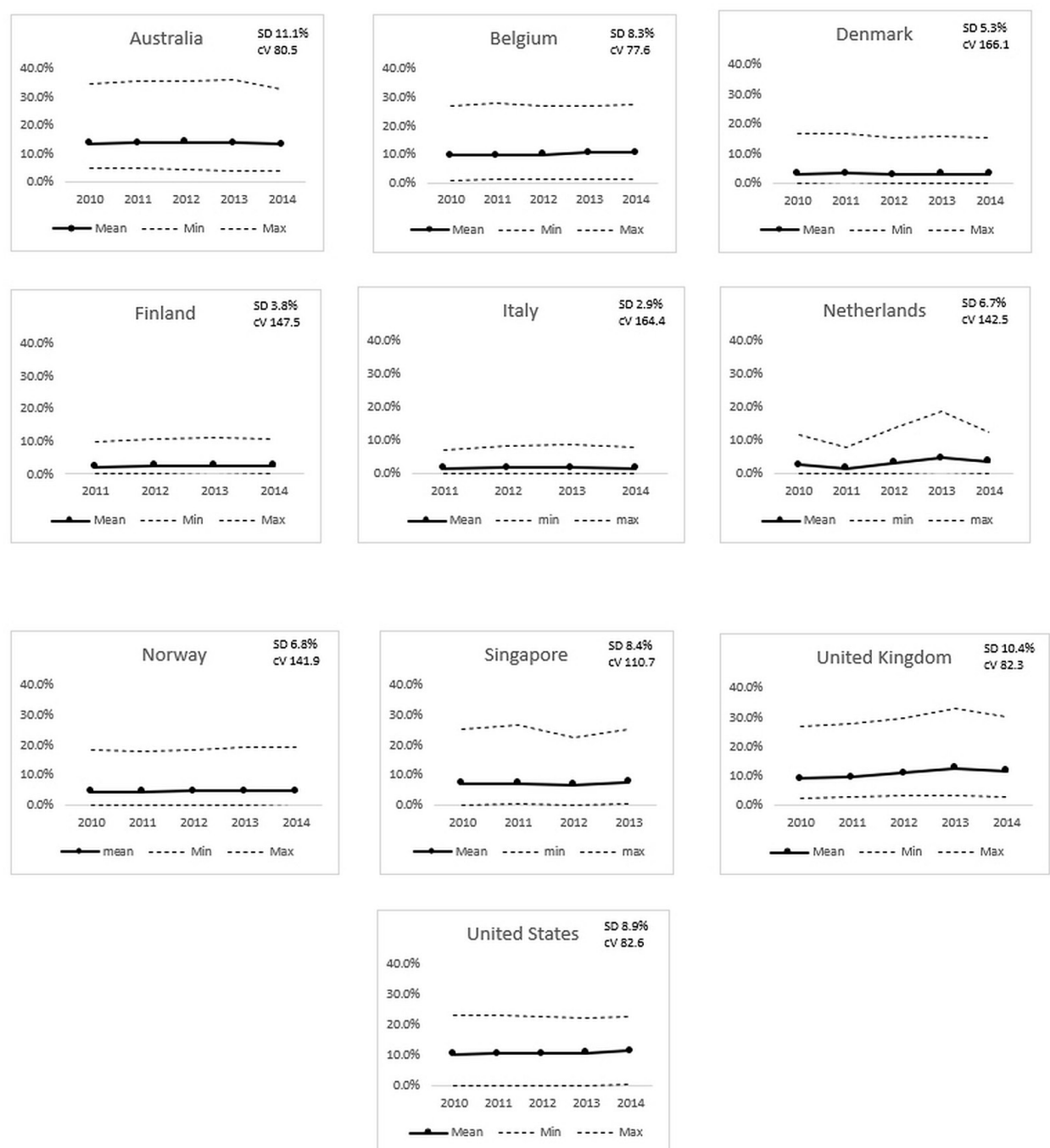

Figure 2 Range and mean across frailty syndrome groups for countries by year. CV, coefficient of variation.

secondary care administrative dataset retain many features that make it a valid measure for identifying frail older persons. In keeping with the literature on frailty, these coded frailty syndromes increase with age and are more common in females and those with emergency admissions to hospital, and have been shown to be related to comorbidity, ${ }^{15}$ thus demonstrating construct validity. It is multidimensional, dynamic over time and computationally

Table 2 Coefficient of variation across all frailty syndrome groups and outcomes for year 2013 within country

\begin{tabular}{lcllc}
\hline Country & $\begin{array}{l}\text { Coefficient of variation across } \\
\text { frailty syndrome groups within } \\
\text { country }\end{array}$ & $\begin{array}{l}\text { Average mortality } \\
\text { rate across frailty } \\
\text { syndromes }\end{array}$ & $\begin{array}{l}\text { Average length of } \\
\text { hospital stay (days) } \\
\text { across frailty syndromes }\end{array}$ & $\begin{array}{l}\text { Average readmission } \\
\text { rate across frailty } \\
\text { syndromes }\end{array}$ \\
\hline Australia & 80.5 & $8.9 \%$ & 18.4 & $11.5 \%$ \\
Belgium & 77.6 & $9.2 \%$ & 20.4 & $8.7 \%$ \\
Denmark & 166.1 & $7.6 \%$ & 8.7 & $15.5 \%$ \\
Finland & 147.5 & $3.4 \%$ & 8.8 & $11.2 \%$ \\
Italy & 164.4 & $7.0 \%$ & 16.6 & $6.2 \%$ \\
Netherlands & 142.5 & $6.3 \%$ & 12.1 & $8.0 \%$ \\
Norway & 141.9 & $5.1 \%$ & 5.8 & $17.3 \%$ \\
UK & 110.7 & $11.9 \%$ & 11.2 & $18.7 \%$ \\
USA & 82.3 & $5.7 \%$ & 17.7 & $14.5 \%$ \\
Singapore & 82.6 & $5.1 \%$ & 9.8 & $21.9 \%$ \\
\hline
\end{tabular}


Table 3 Prevalence of frailty syndromes in observational studies in the secondary care setting

\begin{tabular}{|c|c|c|c|c|c|c|}
\hline Frailty syndrome & $\begin{array}{l}\text { Lakhan et al, } \\
2011^{26}\end{array}$ & $\begin{array}{l}\text { Buurman et al, } \\
2011^{27}\end{array}$ & $\begin{array}{l}\text { Edmans et al, } \\
2013^{28}\end{array}$ & $\begin{array}{l}\text { Bell et al, } \\
2016^{29}\end{array}$ & $\begin{array}{l}\text { Soong et al, } \\
2015^{11}\end{array}$ & This study \\
\hline Anxiety/depression & & $21.1 \%$ & & $29.9 \%$ & $2.4 \%$ & $6.3 \%$ \\
\hline Falls & $41.9 \%$ & $23.3 \%$ & $31 \%$ & $39.2 \%$ & $8.7 \%$ & $23.9 \%$ \\
\hline Incontinence & $36.7 \%$ & $22.2 \%$ & & $38.6 \%$ & $1.1 \%$ & $3.6 \%$ \\
\hline Cognitive impairment & $34.3 \%$ & $40.1 \%$ & $16 \%$ & $25.5 \%$ & $9.0 \%$ & $15.7 \%$ \\
\hline Polypharmacy & & $60.7 \%$ & & & & \\
\hline Malnutrition & & $51.5 \%$ & & $32.8 \%$ & & $4.8 \%$ \\
\hline
\end{tabular}

tractable, demonstrating content validity. It is associated with important clinical outcomes such as mortality and long length of hospital stay, demonstrating criterion validity. ${ }^{22}$

However, between-country and within-country variation in frequency of coded frailty syndromes are noted, as well as some coding instability over time. Overall, this study finds that there is a 5-fold difference between countries for having at least one frailty syndrome group coded $(11.9 \%-56.5 \%)$, and 10-fold difference between the coded frequency of frailty syndrome groups $(2.1 \%-$ $23.9 \%)$. Trend analysis for volume of coded frailty syndromes reveal demarcation between the countries for at least 3 of the frailty syndrome groups. This difference in coding volume between countries could either be a result of coding inconsistencies or, less likely, actual difference in prevalence.

The trend analysis within countries show generally consistent volume of coding of frailty syndrome groups, with two frailty syndrome groups being more prevalently coded compared with the rest, namely 'Falls and Fractures' and 'Dementia and Delirium'. Table 3 displays a summary of the prevalence of frailty syndromes groups in observational studies within the secondary care setting. The prevalence of frailty syndromes in secondary care differs by setting (eg, emergency department vs geriatric ward). However, comparison with observational trials suggest possible under-reporting of frailty syndrome groups within the coded standardised diagnostic fields.

Some countries did exhibit fairly marked coding instability for specific frailty syndrome groups over time (eg, coding of 'Falls and Fractures' in the Netherlands). As standardised diagnostic codes are often used for the purposes of reimbursement, the coding instability may arise in response to changes in local payment structures (eg, Payment by Results), or change in coding processes (eg, the prevalence of coding for 'Senility' has decreased over time in $\mathrm{UK}^{23}$ ).

This study finds a 2.5-fold difference in CV between coded frailty syndrome groups, and 2-fold difference in CV for coding of frailty syndromes between countries. The countries UK, USA, Australia and Belgium appear to have similar variation statistics (table 2) for coded frailty syndrome groups. Though thresholds for CV are context specific, ${ }^{24}$ there does appear to be a natural grouping of coded 'Delirium and Dementia', Falls and Fractures' and Pressure Ulcers and Weight Loss'. Generally, when frequency of coding for frailty syndrome groups or from countries was prevalent, the variation exhibited was lower.

This study finds a twofold, fourfold and twofold difference for outcomes of length of stay, 30-day non-elective readmission and in-hospital mortality, respectively, across the countries. These differences may be a result of patient factors, national health system peculiarities or quality of care provided. Specific coded frailty syndrome groups are associated with different outcomes(eg, 'Pressure Ulcers and Weight Loss with in-hospital mortality). Multivariable adjustment for demographics and comorbidity has shown persistence of these associations, confirming coded frailty syndromes as an independent predictor for the outcomes. ${ }^{12}$ However, there was no correlation between within country $\mathrm{CV}$ and outcomes, across the frailty syndrome groups seen in this study.

The findings of this study have implications for researchers wishing to use standardised diagnostic codes for the purposes of frailty identification. We recommend researchers undertake trend analyses described above to visualise coding frequency and temporal stability to be fully aware of heterogeneity between data groups (eg, countries) and changes in coding frequency over time. For the purposes of population segmentation, grouping countries with similar coding frequencies would remove some data heterogeneity, and improve accuracy of results. For the purposes of risk stratification, finding a period of coding stability for chosen variables is crucial to building a stable prediction model.

We recommend the descriptive statistics described above to quantify variation in the dataset. Researchers may wish to specify thresholds for acceptability of data quality, which can be contextualised to dataset and purpose of analysis. For instance, for a patient-level risk prediction model a CV threshold may be set quite low, where it may be set high or removed for the purposes of international benchmarking of prevalence. 


\section{LIMITATIONS}

Institutions contributing to the dataset are self-selected academic tertiary centres and the findings may not be generalisable to other secondary care institutions. Only one frailty measurement model was used, and this may not be generalisable to other models using similar datasets. ${ }^{25}$ The score was developed on hospitalised populations of age $\geq 75$ years as previous studies have found a larger frequency of coding for frailty syndromes within this age group. This score is, therefore, not validated in those who fall below 75 years of age.

\section{CONCLUSION}

Frailty syndrome groups coded within standardised diagnostic fields of secondary care databases have many features making it a valid measure of frailty. Temporal and geographical variation for coding frailty groups can be quantified and may affect the accuracy and performance of risk prediction models based on this methodology. We recommend the descriptive statistics described above to quantify variation in similar datasets prior to building a risk prediction model.

\section{Acknowledgements Mrs Jurgita Kaubryte was an employee of Dr Foster Telstra} Health, London, UK.

Contributors JTYS conceived study, designed analysis, interpreted results and wrote first draft. JK and SH-XN designed analysis, interpreted results and contributed to ongoing writing. AH and KXQT interpreted results and contributed to ongoing writing. JTYS acts as guarantor.

Funding The work is cofunded by the National University Health System and National University of Singapore. The grant CF/SCL/16/025 was awarded to KXQT for 'Health Innovation Programme-Tackling The Challenge of High-cost Healthcare Users'.

Competing interests $\mathrm{JK}$ had an active role in the analysis of the data and participated in the design of the analysis of this manuscript. The company ( $\mathrm{Dr}$ Foster Telstra Health) collected the data, but did not influence the study design and the data analysis. The company also did not have any influence on the decision to publish or the preparation of the manuscript.

\section{Patient consent for publication Not applicable.}

Ethics approval The data used in this study were collected for administrative purposes and anonymised. As per Governance Arrangements for Research Ethics Committees (GAfREC), research limited to secondary use of information previously collected in the course of normal care (without an intention to use it for research at the time of collection), provided that the patients or service users are not identifiable to the research team in carrying out the research. In Singapore, the study has been undertaken with Domain Specific Research Board approval under the National University Hospital System-National University Singapore Health Innovation Programme-Tackling High Cost Healthcare Users(2016/01011).

Provenance and peer review Not commissioned; externally peer reviewed.

Data availability statement No data are available. Unfortunately, data from the study cannot be made publicly available as the terms and conditions of the research collaboration restricted the availability of original data as follows: (1) Only certain categories of people are permitted to access and use the 'Analytical Tool' (ie, the software processing input data and generating output data for providing benchmarking to each hospital for quality improvements). These are defined as: 'Permitted Users' means the Participant's directors, employees and independent contractors who are authorised by the Participant to access and use the Analytical Tool for the purposes provided in this Agreement. (2) Access to and use of the Analytical Tool itself is granted only for the 'Term' and for specific purposes, being 'accessing and viewing the Output Data and to use the Output Data for the purpose of participating in and reviewing the results of the Project'. The restriction is related to the contract between the participating hospitals and Dr. Foster Telstra Health. There it was specified who has access to the data and that they may not be shared with other people as described above. Other researchers can request access to the data as long as they fulfil the requirements of the contract. Contracting the responsible person in each individual hospital is possible, but the authors cannot guarantee that each hospital will provide the data. This is the responsibility of each hospital. It would be all administrative data of the according years in the participating hospitals. The data are owned by the participating hospitals.

Supplemental material This content has been supplied by the author(s). It has not been vetted by BMJ Publishing Group Limited (BMJ) and may not have been peer-reviewed. Any opinions or recommendations discussed are solely those of the author(s) and are not endorsed by BMJ. BMJ disclaims all liability and responsibility arising from any reliance placed on the content. Where the content includes any translated material, BMJ does not warrant the accuracy and reliability of the translations (including but not limited to local regulations, clinical guidelines, terminology, drug names and drug dosages), and is not responsible for any error and/or omissions arising from translation and adaptation or otherwise.

Open access This is an open access article distributed in accordance with the Creative Commons Attribution Non Commercial (CC BY-NC 4.0) license, which permits others to distribute, remix, adapt, build upon this work non-commercially, and license their derivative works on different terms, provided the original work is properly cited, appropriate credit is given, any changes made indicated, and the use is non-commercial. See: http://creativecommons.org/licenses/by-nc/4.0/.

\section{ORCID iD}

John TY Soong http://orcid.org/0000-0003-4235-8505

\section{REFERENCES}

1 Morley JE, Vellas B, van Kan GA, et al. Frailty consensus: a call to action. J Am Med Dir Assoc 2013;14:392-7.

2 Rockwood K, Song X, MacKnight C, et al. A global clinical measure of fitness and frailty in elderly people. CMAJ 2005;173:489-95.

3 Fried LP, Tangen CM, Walston J, et al. Frailty in older adults: evidence for a phenotype. J Gerontol A Biol Sci Med Sci 2001;56:M146-57.

4 Rockwood K, Fox RA, Stolee P, et al. Frailty in elderly people: an evolving concept. CMAJ 1994;150:489.

5 Ellis G, Whitehead MA, O'Neill D. Comprehensive geriatric assessment for older adults admitted to hospital. [Review]. Cochrane Database of Systematic Reviews, 2011. Available: http://ovidsp. ovid.com/ovidweb.cgi?T=JS\&CSC=Y\&NEWS=N\&PAGE=fulltext\&D= medc\&AN $=21735403$

6 Hogan DB, Maxwell CJ, Afilalo J, et al. A scoping review of frailty and acute care in middle-aged and older individuals with recommendations for future research. Can Geriatr J 2017;20:22-37.

7 Soong J, Balasanthiran A, MacLeod D. National survey of patients with AF in the acute medical unit: a day in the life survey. The British Journal of Cardiology 2013;20:106.

8 Aylin P, Bottle A, Majeed A. Use of administrative data or clinical databases as predictors of risk of death in hospital: comparison of models. BMJ 2007;334:1044.

9 Murray J, Saxena S, Modi N. Quality of routine Hospital birth records and the feasibility of their use for creating birth cohorts, 2012. Available: http://jpubhealth.oxfordjournals.org/content/early/2012/09/ 10/pubmed.fds077.full

10 Palmer WL, Bottle A, Davie C, et al. Meeting the ambition of measuring the quality of hospitals' stroke care using routinely collected administrative data: a feasibility study. Int J Qual Health Care 2013;25:429-36.

11 Soong J, Poots AJ, Scott S, et al. Quantifying the prevalence of frailty in English hospitals. BMJ Open 2015;5:e008456.

12 Soong JTY, Kaubryte J, Liew D, et al. Dr foster global frailty score: an international retrospective observational study developing and validating a risk prediction model for hospitalised older persons from administrative data sets. BMJ Open 2019;9:e026759.

13 Gilbert T, Neuburger J, Kraindler J, et al. Development and validation of a hospital frailty risk score focusing on older people in acute care settings using electronic Hospital records: an observational study. Lancet 2018;391:1775-82.

14 Clegg A, Bates C, Young J, et al. Development and validation of an electronic frailty index using routine primary care electronic health record data. Age Ageing 2016;45:353-60.

15 Soong J, Poots AJ, Scott S, et al. Developing and validating a risk prediction model for acute care based on frailty syndromes. BMJ Open 2015;5:e008457

16 Bottle A, Middleton S, Kalkman CJ, et al. Global comparators project: international comparison of hospital outcomes using administrative data. Health Serv Res 2013;48:2081-100. 
17 Royal College of Physicians. Acute care toolkit 3: acute medical care for frail older people. London: Royal College of Physicians, 2012.

18 Core competencies for the care of older patients: recommendations of the American geriatrics Society. The education Committee writing group of the American geriatrics Society. Acad Med 2000;75:252-5.

19 Banerjee J, Conroy S, Cooke MW. Quality care for older people with urgent and emergency care needs in UK emergency departments. Emerg Med J 2013;30:699-700.

20 Soong JTY, Poots AJ, Bell D. Finding consensus on frailty assessment in acute care through Delphi method. BMJ Open 2016;6:e012904.

21 Lloyd P, Provost SM. The health care data guide: learning from data for improvement, 2011: 480.

22 Rockwood K. What would make a definition of frailty successful? Age Ageing 2005;34:432-4

23 Soong JT, Rolph G, Poots AJ, et al. Validating a methodology to measure frailty syndromes at hospital level utilising administrative data. Clin Med 2020;20:183-8.
24 Reed GF, Lynn F, Meade BD. Use of coefficient of variation in assessing variability of quantitative assays. Clin Diagn Lab Immunol 2002;9:1235-9.

25 Nghiem S, Sajeewani D, Henderson K, et al. Development of frailty measurement tools using administrative health data: a systematic review. Arch Gerontol Geriatr 2020;89:104102.

26 Lakhan $\mathrm{P}$, Jones M, Wilson A, et al. A prospective cohort study of geriatric syndromes among older medical patients admitted to acute care hospitals. J Am Geriatr Soc 2011;59:2001-8.

27 Buurman BM, Hoogerduijn JG, de Haan RJ, et al. Geriatric conditions in acutely hospitalized older patients: prevalence and oneyear survival and functional decline. PLoS One 2011;6:e26951.

28 Edmans J, Bradshaw L, Franklin M, et al. Specialist geriatric medical assessment for patients discharged from hospital acute assessment units: randomised controlled trial. BMJ 2013;347:f5874.

29 Bell SP, Vasilevskis EE, Saraf AA, et al. Geriatric syndromes in hospitalized older adults discharged to skilled nursing facilities. J Am Geriatr Soc 2016;64:715-22. 